\title{
Effect of lung boost device on inspiratory muscle strength in abdominal surgery patients
}

\author{
Amisha. A. Alande ${ }^{* 1}$, Vishnu Vardhan G.D ${ }^{2}$.
}

${ }^{* 1}$ M.P.T Student, Department of Cardiorespiratory physiotherapy, Dr A.P.J Abdul Kalam College of physiotherapy, Loni Ahmednagar, Maharashtra, India.

${ }^{2}$ Associate Professor, Dr A.P.J Abdul Kalam College of physiotherapy, Loni Ahmednagar, Maharashtra, India.

\section{ABSTRACT}

Background: Abdominal surgery involves a surgical repair, resection or reconstruction of organs inside the abdominal cavity. This may include surgery on the stomach, gallbladder, small intestine (colon), liver, pancreas, spleen, esophagus and appendix affected by infection, obstruction, cancerous growth or inflammatory bowel disease. Post Pulmonary Complications (PPCs), are defined as pulmonary anomalies taking place in the postoperative period producing clinically notable, identifiable disease or dysfunction that critically affects the clinical course. As deconditioning is one of the most common and unnecessary causes of morbidity and mortality, the interventions that are implemented should have the potential to increase the strength of the respiratory muscles and accordingly, expand exercise performance and functional capacity as indicated. The aim of the study was to determine the effect of lung boost device on inspiratory muscle strength training in abdominal surgery patients.

Material and Methods: Thirty participants between the age of 20 to 70 years that underwent abdominal surgery were selected and received inspiratory muscle training by lung boost device for twice daily 6 times in a week for 2 weeks. Pre and post intervention assessments were done by PIMax and 6MWD.

Result: Result of this study showed significant difference in the PIMax and 6MWD when treated with Lung Boost device.

Conclusion: The study concluded that use of Lung Boost device causes significant improvement in inspiratory muscle strength and 6MWD in group of abdominal surgery patients and so addition of Lung Boost device in patients with abdominal surgery will increase the strength of inspiratory muscle as well as the functional capacity.

Key Words: Abdominal surgery, Lung Boost device, Maximal inspiratory pressure (PIMax), 6Minute Walk Distance (6MWD).

Address for correspondence: Dr. Amisha. A. Alande, M.P.T Student, Department of Cardiorespiratory physiotherapy, Dr A.P.J Abdul Kalam College of physiotherapy, Loni Ahmednagar, Maharashtra, India. E-Mail: amishaalande6@gmail.com

\begin{tabular}{|l|l|} 
Access this Article online & \multicolumn{2}{|c|}{ Journal Information } \\
\hline Quick Response code & $\begin{array}{r}\text { International Journal of Physiotherapy and Research } \\
\text { ISSN (E) 2321-1822 I ISSN (P) 2321-8975 } \\
\text { https://www.ijmhr.org/ijpr.html } \\
\text { Dol-Prefix: https://dx.doi.org/10.16965/ijpr }\end{array}$ \\
\hline
\end{tabular}

\section{INTRODUCTION}

Surgery is a medical specialty which emphasis on the practice of operative techniques to study and to resolve certain medical conditions caused by disease or traumatic injury and so it has several purposes, such as to improve bodily function, enhance physical appearance and to repair damaged or ruptured areas [1]. According to WHO, as a minimum 321.5 million surgical procedures would be required to report the load of disease for a global population of 6.9 billion as a large volume of 
surgical requirement, approximates that one procedure per 21 people thriving today, with a universal rate of surgery of 4664 per 100 , 000 [2].

Abdominal surgery involves a surgical repair, resection or reconstruction of organs inside the abdominal cavity. This may include surgery on the stomach, gallbladder, small intestine (colon),liver, pancreas, spleen, esophagus and appendix affected by infection, obstruction, cancerous growth or inflammatory bowel disease ${ }^{3}$ upper abdominal surgery included gastrectomy, pancreatectomy, hepatic resection, cholecystectomy and splenectomy [4].

Post Pulmonary Complications (PPCs), are defined as pulmonary anomalies taking place in the postoperative period producing clinically notable, identifiable disease or dysfunction that critically affects the clinical course. Pulmonary function is impaired more severely after abdominal surgery than after non-thoracic or non-abdominal surgery [5].

Postoperative Pulmonary Complications (PPCs) continue to be an important risk of major abdominal surgery (abdominal or upper abdominal between rib cage and umbilicus surgery long-lasting for 3 hours or more), accounting for approximately $25 \%$ of postoperative deaths occurring within 6 days of surgery. The reported incidence of PPCs ranges from $10 \%$ to $88 \%$, depending on the definition used and the population studied [6].

PPC's present high rate of morbidity, mortality and prolonged hospital stay chiefly in abdominal, cardiac and thoracic surgeries. The basic mechanism of PPCs is a lack of lung inflation that occurs because of a change in breathing to a shallow, repetitive breathing pattern without periodic sighs, prolonged recumbent positioning and temporary diaphragmatic dysfunction [7].

According to some authors, surgery lasting for more than $\mathbf{2 1 0}$ minutes is a risk factor for postoperative pulmonary complications [8].

The reduced Functional Residual Capacity (FRC) and impaired oxygenation seen all through during anaesthesia generally return to a standard time in a few hours after minor surgery, but this is not seen in terms of major surgery.
Atelectasis is mainly contemporary in patients in the Post Anaesthesia Care Unit (PACU) [9].

The respiratory muscles are exclusive amongst the skeletal muscles, as they subsequently work without constant rest throughout the life. The respiratory muscles weakness is defined as a decrease in muscle contractility that results in the inability of the respiratory muscles to produce normal levels of pressure and air flow during respiration [10].

Post- operative abdominal surgery, due to direct or indirect trauma to the diaphragm there are consequences resulting in decrease in maximum static respiratory pressures (MRPs), specifically the maximum inspiratory pressure (PIMax) and maximum expiratory pressure (PEMax), which replicate the strength of the respiratory muscles and so diaphragm function can be weakened by reflex paresis, and due to the synergetic activity of abdominal muscles its inspiratory is action reduced [11].

Inspiratory Muscle Training (IMT) training helps to reduce the level of dyspnea and improves the pulmonary function, respiratory muscle strength and functional capacity [12].

Lung Boost is a device used for respiratory muscles training. Numerous researches have revealed that using a Respiratory Muscle Training (RMT) device, with adding a fitness regime like walking, progresses the strength and endurance of the respiratory muscles and so the other improvements may comprise longer walking distance, reduction in shortness of breath, better quality of life and a general feeling of wellbeing.

Lung Boost is planned for anyone who wishes to improve the strength and endurance of respiratory muscles in an individual, including professional athletes, recreational athletes and healthy individuals. However, this device is not indicated for the people who are too weak or ill to use the device [13]

Maximal Inspiratory Pressure (PIMax) is an significant indicator to assess the inspiratory muscles strength, also its used as a diagnostic parameter in patients with diminished respiratory muscle strength [14]. as most of the activities of daily living are completed at 
sub-maximal levels of exertion, the 6MWD may imitate the functional exercise level for daily physical events [15].

\section{METHOD AND METHODOLOGY}

The research design used for the study was Experimental study. The source of data and the study conducted was from Inpatient department of Surgery, Pravara Rural Hospital, Ioni, Taluka- Rahata, Dist. Ahmednagar, Maharashtra state, India - 413736. The data was collected by the Principal Investigator. The duration of the study was 1 year. The target population for the study was patients with abdominal surgery. The sample size was thirty and simple random sampling method was used in this study. The patients included were Participants ready to give written consent form. Both male and female participants. Participants who underwent upper abdominal surgeries. Participants within the age group of 20-70 years admitted in Pravara Rural Hospital The patients excluded Participants who were haemo-dynamically unstable. Symptomatic heart disease, including congestive heart failure, arrhythmia or myocardial infarction diagnosed within the three months. Chronic debilitating conditions, rib fractures, thoracic vertebra fracture, acute pleuritic chest pain.

The outcome measures were Maximum Inspiratory Pressure (PIMax)-The measurements were taken with participants in sitting position, with or without nose clips. Participants were asked to exhale to Residual Volume (RV) and then perform a maximal inspiratory effort, sustaining it for 1 to 2 seconds. The manoeuvre was repeated at least three times, and then the average was taken. Pressures had to be maintained for at least one second. An interval of about one minute occurred between this efforts. Efforts must be sustained for at least 1.5 seconds in order that an average pressure over 1 second can be calculated by hand held pressure manometer device. Because of the length tension relationship of the respiratory muscles, maximal inspiratory pressure (MIP) is measured at residual volume.

6-Minute Walk Distance -It is a sub maximal exercise test used to assess the functional capacity of patient. It is a simple test that requires a $100-\mathrm{ft}$ hallway but no exercise equipment's. The distance that the participants was able to walk in 6 min was determined in a measured corridor The participants were instructed to walk at their fastest pace and to cover the longest possible distance over 6 min under the supervision of a physiotherapist. The normal values for 6MWD ranges from 400-700m. In Procedure total thirty participants $(n=30)$ were selected and screened according to inclusion and exclusion criteria. Before starting the intervention, participants were assessed for the baseline parameters of PIMax and 6MWD. The intervention was given for 6 days in a week for 2 weeks twice a day. The duration for each session was of 15-20 minutes which also includes rest periods and 3 set of 10 repetitions for Lung boost device. After 2 weeks of intervention baseline parameters were reassessed. The Lung Boost Device was used by instructing the participants to hold mouthpiece with lips and not with teeth as this may cause undue jaw pressure and inadequate lip seal, difficulty level was chosen They were asked to breath in through the mouthpiece (not the nose) for 2-3 seconds, slight pause (under a second), then exhale. Instruction was given to raise the abdomen slightly during inspiration. However there were four dropouts and 1 death of the participants in the study.

Intervention: Participants received respiratory muscle training through the Lung Boost device. Participants were in sitting position, for strength training and strength mode on the device was pressed and difficulty level was chosen starting with level 1 and with the breathing tube and mouth piece promptly attached, patient was asked to gently inhale through the mouth piece. As the patient inhaled the effort would be indicated by the highest number of the ball on the right side of the display and after every exercise resting period of 15seconds on top of screen was given to prevent hyperventilation or muscle fatigue. If the participant would reach all the 7 balls too easily the level was increased by pressing level button and if the participant would reach 
the highest ball on level 5, difficulty was increased by attaching resistance cone to the back of the unit. As the resistance cone was attached patient would begin training again from level 1.

Participants were instructed to inhale deeply and forcefully for 2-3 seconds, slight pause, then exhale forcefully for 2-3 seconds for 10 repetition 2 sets.

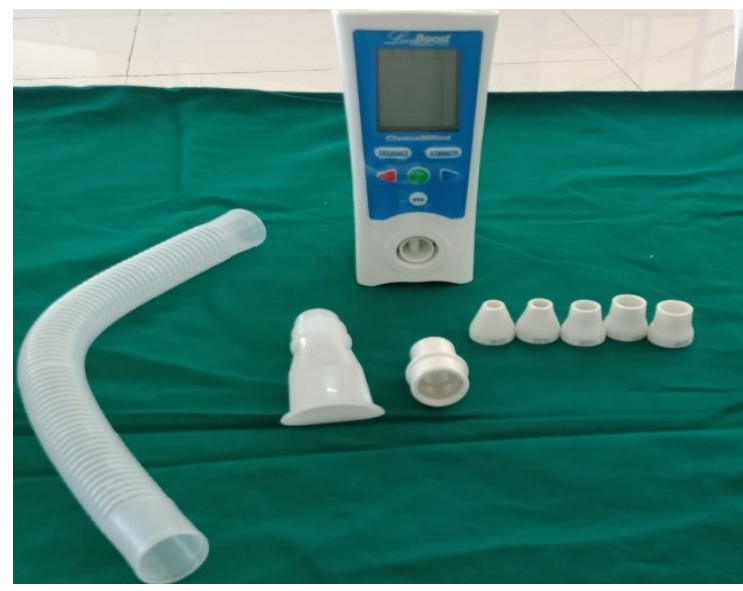

Image 1: Lung Boost device.

\section{RESULTS}

The data was entered in the excel spread sheet tabulated and subjected to statistical analysis. Data was analyzed using Graph Pad Instat Trial Version 13.3. Descriptive statistics for all outcome measures were expressed as mean, standard deviations and test of significance such as Paired ' $\mathrm{t}$ ' test. The confidence interval was set at $95 \%$ and data was considered statistically significant with $p<0.05$ and highly or considerably significant with $p<0.001$.

Table1: Demographic data of participants in the group

\begin{tabular}{cc}
\hline Gender & Group \\
\hline Male & 13 \\
Female & 12 \\
Total & $\mathbf{2 5}$ \\
\hline
\end{tabular}

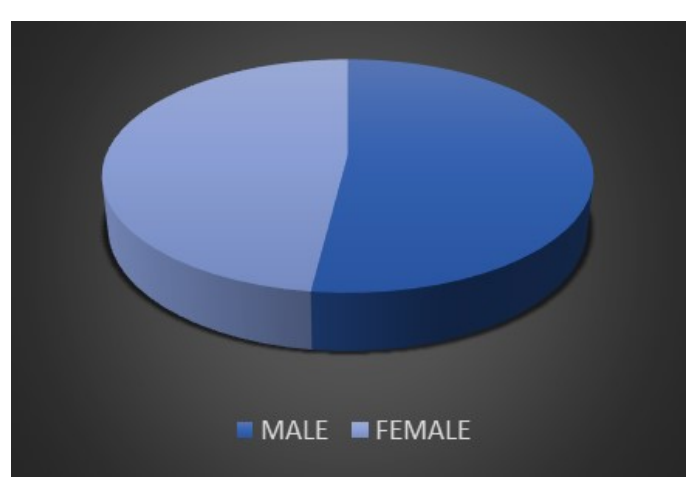

Graph 1: Demographic data of participants in groups. 2. Maximal Inspiratory Pressure (PIMax)
Table 2: Pre-Post Comparison of PIMax in the group.

\begin{tabular}{ccccc}
\hline \multirow{2}{*}{ Group } & $\begin{array}{c}\text { PRE MEAN } \\
\text { SD }\end{array}$ & $\begin{array}{c}\text { POST MEAN } \\
\text { SD }\end{array}$ & t value & p value \\
\cline { 2 - 5 } & $53.8 \pm 7.25$ & $70.2 \pm 9.06$ & 10.05 & $\begin{array}{c}<0.0001 \text { Highly } \\
\text { significant }\end{array}$ \\
\hline
\end{tabular}

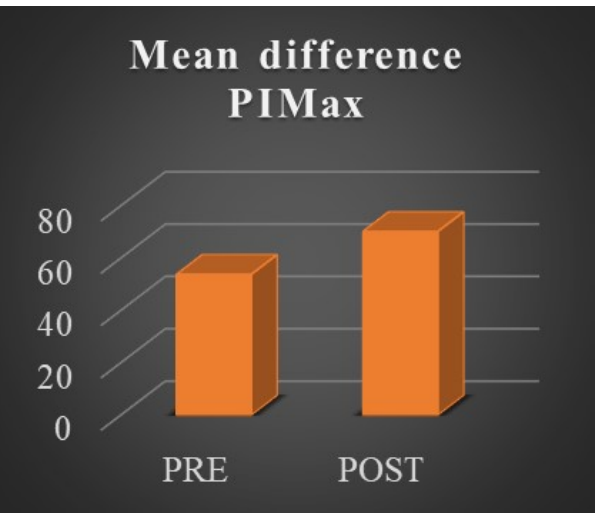

Graph 2 : Mean Difference in PIMax in the Group The strength of diaphragm was assessed by measuring maximal inspiratory pressure by using hand held pressure device. The mean baseline value for PIMax in the group preintervention was 53.8 with standard deviation of \pm 7.25 and post-intervention was 70.2 with standard deviation of \pm 9.06 . The differences in the baseline parameter for PIMax by participants in the group was highly significant $(p<0.0001, t=10.05)$.

1.Six Minute Walk Distance (6MWD)

Table 3: Pre-Post Comparison of 6MWD in the group.

\begin{tabular}{ccccc}
\hline \multirow{2}{*}{ Group } & PRE MEAN SD & POST MEAN SD & t value & p value \\
\cline { 2 - 5 } & $256.56 \pm 24.42$ & $340.76 \pm 37.60$ & 11.93 & $\begin{array}{c}<0.0001 \text { Highly } \\
\text { significant }\end{array}$ \\
\hline
\end{tabular}

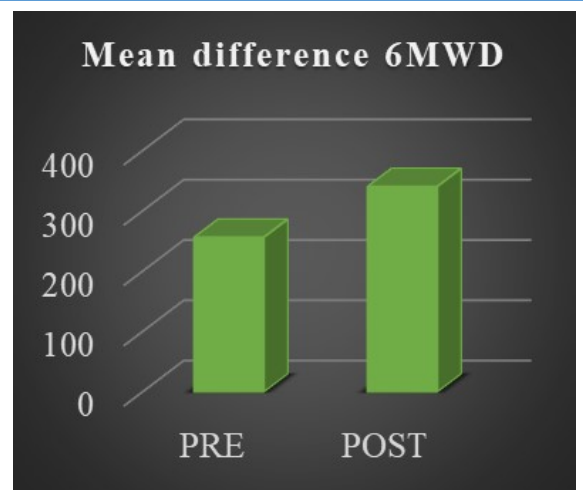

Graph. 3: Pre-Post 6 MWD in the Group 6MWD was measured on day 1 and day 14 of intervention of Participants. The mean baseline value for 6MWD in the Group pre-intervention was 265.56 with standard deviation of \pm 24.42 and post-intervention was 340.76 with standard deviation of \pm 37.60 . The differences in the baseline parameter for 6MWD by participants was highly significant $(p<0.0001, t=11.93)$. 


\section{DISCUSSION}

The main purpose of this study was to determine the effect of the Lung Boost device on inspiratory muscles training in participants with abdominal surgeries.

Maximum of the studies have been engrossed on the use of Inspiratory Muscle Training (IMT) device in various respiratory, neurological and surgical conditions to prevent postoperative pulmonary complications and also for improving the strength of respiratory muscles, but there are very few evidence on the use of the Lung Boost device in patients with abdominal surgeries. The result obtained in the present study showed that, there was highly significant difference in the PIMax and 6MWD after 2 weeks of intervention in abdominal surgeries.

Inspiratory muscle strength was measured by using hand held pressure manometer device (PIMax) for Pre and Post intervention measuring from $-400 \mathrm{cmH} 2 \mathrm{O}$ (inspiratory) to +400 $\mathrm{cmH} 2 \mathrm{O}$ (expiratory). In the group mean difference pre intervention was $53.8 \pm 7.25$ $\mathrm{cmH} 2 \mathrm{O}$ and post intervention was $70.2 \pm 9.06$ $\mathrm{cmH} 2 \mathrm{O}$. Comparison of the mean difference confirmed that there was a highly significant $(p=<0.0001, t=10.05)$ difference between the pre and post intervention in the group by using student paired ' $\mathrm{t}$ ' test.

Surgical duration, anaesthesia, impaired respiratory function, worsen mucociliary clearance and suppression of cough reflex leading to secretion retention and reduced lung volumes contributes to atelectasis thereby developing of infection ${ }^{16}$.Post-operatively ,anaesthetics and analgesic agents causes distress to upper airway and accessory muscle function, increasing the risk of Post-operative Pulmonary Complications (PPC's) [17].

A Randomized Controlled Trial(RCT) was conducted by Weiner $P$ et.al which inspected the effect of postoperative IMT on respiratory muscle strength after lung cancer surgery where study included 32 patients with chronic obstructive pulmonary disease, in which IMT was performed 2 weeks preoperatively and it was been sustained for 2 months after the surgery. The authors reported $13 \%$ increase in respiratory muscle strength in the active arm, whereas a respiratory muscle strength decrease was reported markedly in controls [18]. The functional capacity of participants was evaluated by using 6MWD. The mean difference of pre intervention for 6MWD in the group was $256.56 \pm 24.42 \mathrm{~m}$ and after 2 weeks of intervention was $340 \pm 37.60 \mathrm{~m}$. Comparison of these values confirmed that there was a highly significant $(p=<0.0001, t=11.93)$ difference between the pre and post intervention in the group using paired test.

The respiratory muscle metaboreflex has been found to play a very important part in limiting respiratory and limb muscle perfusion during exercise [19].

IMT may reduce the Work Of Breathing(WOB), metabolic rate of breathing and perception of nervous system's with inspiratory output, so that dyspnea and exercise capacity would be improved. Peripheral muscle weakness also results in exercise intolerance and a study suggested that blood flow is distributed from respiratory to locomotor muscle during unloading breathing. IMT may increase blood flow to peripheral muscles so that peripheral muscle strength and also exercise capacity should be improved [20].

T. D. Mickleborough et.al demonstrated in a study that Inspiratory Flow Resistive Loading (IFRL) given for 3 days/week for 6 weeks would (1)modify breathing mechanics, lower the oxygen cost and reduce ventilatory, $H R$, [Lac]B and the perceptual response during constant workload exercise, (2) increase inspiratory muscle strength, endurance, Maximal Inspiratory Muscle Power Output (IMPOmax) and Inspiratory Muscle Work Capacity (IMWC) and (3) improve exercise routine of recreational runners during a laboratory treadmill running time to exhaustion test at $80 \%$ of VO2max [21]. Romer et.al and Gething et.al studied that, the mechanisms answerable for the ergogenic eûect of RMT on exercise performance are indeterminate, but recent evidence suggests that IMT may produce improvements in exercise performance over two foremost mechanisms which are interrelated: (1) diminution of eûort sensations, such that exercise feels easier following IMT (22)(23)and (2) diminution of the 
inspiratory muscle metaboreûex leading to a perseveration of limb locomotor blood ûow during exercise which was studied by Witt et al [24].

Even though the breathing exercises can enhance the inspiratory muscle strength, It was found that use of Lung Boost device to be more effective in improving the inspiratory muscle strength as breathing against resistance during inspiratory muscle training activates and strengthens inspiratory muscle. It enhances the functional capacity of the patients by improving the quality of life backing regained activity and exercise tolerance. It not only strengthens the respiratory muscle but also assist to breathe appropriately and efficiently through the resistance offered by the device. The Lung Boost device functions as a therapeutic exerciser for the lungs reducing in shortness of breath. In addition there is reduction of the postoperative anxiety in patients, and also helps to build self confidence.

\section{CONCLUSION}

The present study showed that the use of Lung Boost device causes significant improvement in inspiratory muscle strength and 6MWD in the group of abdominal surgery participants increasing increase the strength of inspiratory muscle as well as the functional capacity.

\section{Conflicts of interest: None}

\section{REFERENCES}

[1]. http://www.upmc.com/SERVICES/GENERAL-SURGERY-TRAUMA/RESEARCH/Pages/default.aspx

[2]. Rose J, Weiser TG, Hider P, Wilson L, Gruen RL, Bickler SW. Estimated need for surgery worldwide based on prevalence of diseases: a modelling strategy for the WHO Global Health Estimate. The Lancet Global Health. 2015 Apr 27; 3: S 13-20.

[3]. Pushpal K Mitra: Textbook of PHYSIOTHERAPY in Surgical Conditions, Chapter 3, page no 29 and 32.

[4]. Kim TH, Lee JS, Lee SW, Oh YM. Pulmonary complications after abdominal surgery in patients with mild-to-moderate chronic obstructive pulmonary disease. International journal of chronic obstructive pulmonary disease. 2016; 11: 2785.

[5]. Alagol A, Anesthetic Management of Abdominal Surgery [Internet] 2012; Available from http://dx.doi.org/10.5772/49940.

[6]. O, Deborah L, et.al; The Effect of Abdominal Support on Functional Outcomes in Patients Following Major Abdominal Surgery: A Random ized Controlled Trial. Physiotherapy Canada, 2010; 62:242-253.

[7]. M, Celso Ricardo C et.al, Chest physiotherapy during immediate postoperative period among patients undergoing upper abdominal surgery: randomized clinical trial. Sao Paulo Med J. 2008; 126(5):269-73.

[8]. Celso R, Carvalho, Denise M.Paisani, et.al, Incentive spirometry in major surgeries: A systemic review. Rev Bras Fisioter.2011; 15(5):343-5.

[9]. Miskovic A, Lumb AB. Postoperative pulmonary complications. BJA: British Journal of Anaesthesia. 2017 Mar 1;118(3):317-34.

[10]. De Menezes KK, Nascimento LR, Ada L, Avelino PR, Polese JC, Alvarenga MT, Barbosa MH, TeixeiraSalmela LF. High-Intensity Respiratory Muscle Training Improves Strength and Dyspnea Poststroke: A Double-Blind Randomized Trial. Archives of physical medicine and rehabilitation. 2018 Oct 12.

[11]. Mayura P. Deshmukh, G. D. Vishnu Vardhan, Dr. Tushar J. Palekar. A study on effect of inspiratory muscle training in upper abdominal surgery patients. International Journal of Pharma and Bio Sciences 2017 October; 8(4): (B) 378-384

[12]. Neves LF, Reis MH, Plentz RD, Matte DL, Coronel CC, Sbruzzi G. Expiratory and expiratory plus inspiratory muscle training improves respiratory muscle strength in subjects with COPD: systematic review. Respiratory care. 2014 Apr 29:respcare-02793

[13]. .www.choicemmedamerica.com .

[14]. Weindler J, Kiefer RT. The efficacy of postoperative incentive spirometry is influenced by the devicespecific imposed work of breathing. Chest. 2001 Jun 1;119(6):1858-64.

[15]. ATS Committee on Proficiency Standards for Clinical Pulmonary Function Laboratories. ATS statement: guidelines for the six-minute walk test. Am J Respir Crit Care Med. 2002;166:111-7.

[16]. Patman S, Bartley A, Ferraz A, Bunting C. Physiotherapy in upper abdominal surgery-what is current practice in Australia?. Archives of physiotherapy. 2017 Dec 1;7(1):11.

[17]. Canet J, Mazo V. Postoperative pulmonary complications. Minerva Anestesiol 2010; 76: 138-43.

[18]. Weiner P, Man A, Weiner M, Rabner M, Waizman J, Magadle $R$ et al. The effect of incentive spirometry and inspiratory muscle training on pulmonary function after lung resection. J Thorac Cardiovasc Surg 1997;113: 552-7.

[19]. Sheel AW, Derchak PA, Morgan BJ, Pegelow DF, Jacques AJ, Dempsey JA. Fatiguing inspiratory muscle work causes reflex reduction in resting leg blood flow in humans. The Journal of Physiology. 2001 Nov;537(1):277-89.

[20]. Bosnak-Guclu M, Arikan H, Savci S, Inal-Ince D, Tulumen E, Aytemir K, Tokgözoglu L. Effects of inspiratory muscle training in patients with heart failure. Respiratory medicine. 2011 Nov 1;105(11):1671-81. 
[21]. Mickleborough TD, Nichols T, Lindley MR, Chatham $\mathrm{K}$, lonescu AA. Inspiratory flow resistive loading improves respiratory muscle function and endurance capacity in recreational runners. Scandinavian journal of medicine \& science in sports. 2010 Jun;20(3):458-68

[22]. Romer LM, McConnell AK, Jones DA. Effects of inspiratory muscle training on time-trial performance in trained cyclists. Journal of sports sciences. 2002 Jan 1;20(7):547-90.
[23]. Gething AD, Williams M, Davies B. Inspiratory resistive loading improves cycling capacity: a placebo controlled trial. British journal of sports medicine. 2004 Dec 1;38(6):730-6

[25]. Witt JD, Guenette JA, Rupert JL, McKenzie DC, Sheel AW. Inspiratory muscle training attenuates the human respiratory muscle metaboreflex. The Journal of physiology. 2007 Nov 1;584(3):1019-28.

How to cite this article:

Amisha. A. Alande, Vishnu Vardhan G.D. Effect of lung boost device on inspiratory muscle strength in abdominal surgery patients. Int J Physiother Res 2021;9(2):3793-3799. DOI: 10.16965/ijpr.2021.109 